Коркоценко Марина Николаевна

кандидат педагогических наук, доцент кафедры гуманитарных и социально-экономических дисциплин Краснодарского высшего военного авиационного училища летчиков имени Героя Советского Союза А.К. Серова

\section{ОБЗОР ОПРЕДЕЛЕНИЙ КАТЕГОРИИ «ЭКОНОМИЧЕСКОЕ МЫШЛЕНИЕ» В НАУЧНОЙ ЛИТЕРАТУРЕ}

\section{Аннотация:}

В статье представлены взгляды российских и зарубежных экономистов-теоретиков и практиков на современное экономическое мышление, произведен сравнительный анализ существующих подходов, выявлены их сильные и слабые стороны. Автор приходит к заключению, что экономическое мышление - это категория, которая может быть рассмотрена только в комплексе подходов разных гуманитарных областей, на основе собственного практического опыта и мировоззрения человека.

\section{Ключевые слова:}

понятие "экономическое мышление», теоретиче ская экономика, практическая экономика, истори ческий подход, логический метод, нормативная экономика, позитивная экономика, субъективизм.
Korkotsenko Marina Nikolayevna

PhD in Education Science, Assistant Professor Humanities and Socio-Economic Subjects Department, Krasnodar High Military School of Aviation

\section{REVIEW OF "ECONOMIC THINKING" DEFINITION IN THE SCIENTIFIC LITERATURE}

Summary:

The article presents the views of Russian and foreign economic theorists and practitioners on modern economic thinking, provides a comparative analysis of the existing approaches, identifies their strengths and weaknesses. The author comes to the conclusion that economic thinking is a category, which can be considered only in the complex approaches of different humanitarian areas on the basis of the human's practical experience and worldview.

Keywords:

"economic thinking" concept, theoretical economics, practical economics, historical approach, logical method, normative economics, positive economics, subjectivism.

Современные тенденции в развитии экономической науки в России и за рубежом открывают большие перспективы для теоретического изучения и практического исследования различных точек зрения на фрормирование экономического мышления.

Существующие тенденции развиваются в рамках экономической теории и указывают на связь формируемого мышления и уровней экономики. К такой точке зрения следует отнести взгляд доктора экономических наук К.А. Улыбина. Согласно автору, экономическое мышление существует в рамках экономической системы. Оно сводится к процессу воспроизведения в сознании хозяйствующего субъекта сначала законов его поведения, функционирования и становления самой системы, затем прогнозирования и планирования ее развития [1].

Приведенная модель К.А. Улыбина имеет положительные и отрицательные стороны. Преимущества связаны с попыткой соединить законы теоретической экономики и характер отношений экономических субъектов с практическими условиями функционирования хозяйственной системы и особенностями желаний и потребностей людей.

Несмотря на то что ученый попытался избежать развития синдрома «неспособности трансформации теоретической экономики в практические действия», такое видение экономического мышления имеет ряд недостатков. Во-первых, представление о связи теоретических законов и положений с практической деятельностью людей и предприятий (организаций) будет носить объективный характер только тогда, когда отношения будут строиться с учетом внешних фракторов (социальных, политических, технологических, международных, экологических и т. д.), а оценка будет даваться комплексно, в сочетании с науками и областями, связанными с экономикой. Во-вторых, на всех уровнях мышления речь должна идти о гибко меняющихся законах, содержание которых напрямую зависит от внешних фракторов и состояния экономики.

В понимании доктора экономических наук, профессора Е.Ф. Борисова надлежит говорить уже не о рассудочном, а об обыденном экономическом мышлении [2]. Это попытка автора перевести область изучения экономики в научную среду для возможности объективного анализа хозяйственной деятельности. Преимущество научного экономического мышления, с нашей точки зрения, состоит во всестороннем и целостном отражении экономики.

Е.Ф. Борисовым верно замечено, что исторический подход в анализе хозяйственной деятельности человека, предприятия и экономики государства может затруднить теоретическое изу- 
чение экономики. Обилие фактов, архивных документов и исторических подробностей может нечетко раскрыть черты систем производства. Логический метод позволит преодолеть недостатки. Его законы служат непременным условием достижения истинности высказываемых положений и выводов, что помогает глубже понять причинно-следственные зависимости в экономике. Полученные теоретические и практические выводы используются для прогнозирования и улучшения управления хозяйством.

В методологии экономических исследований Е.Ф. Борисова сегодня можно выделить один недостаток. Для создания подобного образа экономического мышления, когда логический метод сочетается с историческим, имеет значение уровень образования и сформированности общих и профрессиональных компетенций. Не обладая достаточными знаниями, трудно представить любую систему, в данном случае экономическую, в виде единого целого комплекса. Следовательно, исследование прошлых исторических этапов в настоящем всегда будет содержать загадки. Поэтому исторически выделенные в законы и принципы положения должны преломляться по отношению к существующим условиям бытия.

Экономисты-практики в своей повседневной деятельности опираются на логические заключения и выводы о причинах и следствиях тех или иных экономических процессов на основе собственных умозаключений. Степень абстрагирования от реальности высока, и теоретические модели могут развиваться до некоторой степени независимо от объясняемых и моделируемых явлений.

B.C. Автономов, чтобы разобраться в сложном отношении экономистов к экономической методологии, предлагает различать нормативную и позитивную методологию экономической науки [3, с. 12]. Первая - моральный кодекс профессии, содержащий описание идеала, к которому надо стремиться. Вторая - попытка осознать и обобщить практику исследований в данной области науки. Видно, что создание определенного образа экономического мышления в таком случае будет связано с философским аспектом принимаемой модели поведения и образа мысли и сознания.

Подобными вопросами задавались не только российские, но и иностранные экономисты. М. Блауг, американский и английский экономист, в своей книге «Экономическая мысль в ретроспективе» [4, с. 6-7] отмечал, что развитие экономической мысли не происходило в виде однозначно линейного движения к нынешним истинам. С позиции формирования экономического мышления современности (в начале второго десятилетия XXI в.) идеи М. Блауга могут быть дополнены некоторыми положениями. Нам они видятся так. Основой для собственного мышления человека служит не столько философская основа науки - методология, сколько интерпретация основных положений в индивидуальном понимании, с анализом собственных действий и поступков, осознание результатов своего труда. Как следствие, мышление фрормирует мотивацию поведения и деятельности человека.

Известные американские экономисты С. Фишер, Р. Дорнбуш и Р. Шмалензи, в отличие от М. Блауга, придерживались иной точки зрения. Формирование экономического мышления возможно, если сочетать экономику с прикладными науками, с фактическими результатами в рамках нескольких стран и экономических систем [5, с. 28]. Полезность теоретических положений, по мнению авторов, непременно связана с конкретными случаями экономической жизни стран.

Проведенный анализ позиции С. Фишера, Р. Дорнбуша и Р. Шмалензи позволил сделать вывод о неоднозначности предположения авторов. Так как человек может анализировать методы исследования и давать всестороннюю оценку наблюдаемой действительности, он получает возможность самостоятельно прийти к правильным действиям. Основание для этого - всесторонний анализ событий и ситуаций, понимание и осознание собственной роли и места в экономических процессах. Подобный подход к выработке экономического мышления дает человеку чувство сопричастности к формированию экономики страны. Однако велика вероятность развития субъективизма в мышлении, гранью которого может стать потребительское поведение, тормозящее развитие экономики.

Этой проблемой косвенно интересовался американский экономист П. Хейне. С его точки зрения, экономика помогает приходить к правильным заключениям тому, кто владеет ею, а значит, выступает методом познания, интеллектуальным инструментом (информационной средой) [6]. Вопрос лишь в том, что для человека будет важным, полезным и выгодным.

Ряд авторов (Л.И. Абалкин, В.Н. Амелин, В.Д. Попов, Г.Н. Соколова, Л.И. Чернышева) рассматривают экономическое мышление как проявление экономического сознания в конкретной ситуации. Доктор экономических наук А.Ю. Архипов дополняет данное авторами определение и предлагает обратить внимание на процесс познания экономической действительности, экономических отношений и осознание своего места в них. На процесс его формирования влияют экономическая наука, образование и воспитание [7, с. 8-12]. Заметим, что некоторые ученые-экономисты в своих исследованиях идут дальше и предлагают представить процесс развития экономи- 
ческого мышления как последовательное исследование экономического объекта и его существенных признаков. Дополнить такое представление можно, изучив особенности правовых норм деятельности хозяйствующих субъектов, рассмотрев права и обязанности человека.

В статье приведены лишь некоторые представления ученых-экономистов об экономическом мышлении. Но и этого достаточно, чтобы сделать некое обобщение взглядов: идеи теоретиков и практиков в области экономики, какими бы разными они ни были, сводятся к одному знаменателю.

Экономическое мышление - это категория, которая может быть рассмотрена только в комплексе подходов разных гуманитарных областей, на основе собственного практического опыта человека и сложившегося мировоззрения. Объективный анализ современных событий и ситуаций из практической жизни возможен только в сочетании с теоретическими вопросами и методологической базой. Истинные причины проблемы состоят в исторических особенностях развития общественных отношений, центром интересов которых выступает сам человек и его стремление к чистой выгоде в разных формах. Экономическое мышление определяется сознанием человека и приводит к определенному образу экономического поведения. Логическая связь современных событий и исторических процессов доказывает необходимость системного анализа и детального рассмотрения всех процессов хозяйственной жизни субъектов экономики и экономической политики общества.

\section{Ссылки:}

1. Улыбин К.А. Современное экономическое мышление: политико-экономические аспекты исследования и формирования : автореф. дис. ... д-ра экон. наук. М., 1989. 47 с.

2. Борисов Е.Ф. Методология экономических исследований [Электронный ресурс] // Борисов Е.Ф. Экономическая теория. URL: http://www.booksite.ru/localtxt/bor/iso/borisov e/ekon teor/index.htm (дата обращения: 06.02.2017).

3. Блауг М. Методология экономической науки, или Как экономисты объясняют : пер. с англ. / науч. ред. и вступ. ст. В.С. Автономова. М., 2004. С. 12.

4. Блауг М. Экономическая жизнь в ретроспективе. М., 1994. С. 6-7.

5. Фишер С., Рудигер Д., Шмалензи Р. Экономика : пер. с англ. со 2-го изд. М., 1995. С. 28.

6. Хейне П. Экономический образ мышления [Электронный ресурc]. URL: http://polbu.ru/hejne_economicthinking (дата обращения: 07.12.2016).

7. Архипов А.Ю. Современное экономическое мышление (Вопросы теории и практики развития) : дис. ... д-ра экон. наук. Ростов н/Д., 1999. С. 8-12.

\section{References:}

Arkhipov, AYu 1999, Modern economic thinking (Issues of theory and practice of development), Rostov-on-Don, pp. 8-12, (in Russian).

Blaug, M 1994, Economic life in retrospect, Moscow, pp. 6-7, (in Russian).

Blaug, M \& Avtonomova, VS (ed.) 2004, Methodology of economic science, or how economists explain, Moscow, p. 12, (in Russian)

Borisov, EF 2017, 'Methodology of economic research', Ekonomicheskaya teoriya, viewed 06 February 2017, <http://www.booksite.ru/localtxt/bor/iso/borisov e/ekon teor/index.htm>, (in Russian).

Fischer, S, Rudiger, D \& Shmalenzi, R 19̄̄5, Economy, 2nd ed., Moscow, p. 28, (in Russian).

Heine, P 2016, The economic way of thinking, viewed 07 February 2016, <http://polbu.ru/hejne economicthinking>, (in Russian).

Ulybin, KA 1989, Modern economic thinking: political and economic aspects of research and formation, D.Phil. in Economics thesis abstract, Moscow, 47 p., (in Russian). 